\title{
Phenotypic Variation in Freshwater Murrel, Channa punctatus (Bloch, 1793) from Northern and Eastern Regions of India Using Truss Analysis
}

\author{
Ankur Kashyap, Madhu Awasthi, and Mohammad Serajuddin \\ Department of Zoology, University of Lucknow, Lucknow, Uttar Pradesh 226007, India \\ Correspondence should be addressed to Mohammad Serajuddin; lu.fisheries@gmail.com
}

Received 31 October 2015; Accepted 13 January 2016

Academic Editor: Michel Laurin

Copyright (C) 2016 Ankur Kashyap et al. This is an open access article distributed under the Creative Commons Attribution License, which permits unrestricted use, distribution, and reproduction in any medium, provided the original work is properly cited.

Morphometric variation study was carried out using truss analysis in freshwater murrel, Channa punctatus (Bloch, 1793), to explore different phenotypic stocks of $C$. punctatus. Significant variation in the morphometric analysis was observed using the truss network and multivariate analysis of the three subpopulations of freshwater murrel, C. punctatus, from the two different regions of India. Principal component analysis accounted for a total variation of $91.95 \%$ by the first three principal components. PC 1 represented the variation due to size and PC 2 and PC 3 represented variations due to shape. The 95\% confidence ellipses depicted the clear isolation between the samples in scatter graph of PC 1 on PC 2. The combined groups plot (DF 1 on DF 2) based on discriminant function analysis (DFA) also validated the existence of three different subpopulations. In group classification using DFA, 100 percent of all the samples were correctly classified into their original subpopulation. These results support the existence of multiracial composition of $C$. punctatus across the different geographical isolated sites and, thus, these findings indicate the presence of three different phenotypic stocks of C. punctatus.

\section{Introduction}

Stock identification is considered to be an important aspect in the field of fishery management because the stocks with variable life history attributes such as growth and reproductive potentials are considered to be important to increase yield and also for stock improvement programme of fish. Variation in the growth, development, and maturation in different members of the same species results in variety of body shapes [1]. Patterns of morphometric variation in fishes indicate differences in growth and maturation rates because the body forms are products of ontogeny. The multiple stock compositions of the fish were reported by many workers [24].

The truss network system was used by many notable workers to segregate the stocks [5-7]. The truss analysis is important because it covers the entire shape of the fish in a form of a uniform network, and thus the probability of extracting the morphometric differences among the different fish populations is increased. Working on Indian fishes like
Catla catla, Rastrelliger kanagurta, and Megalaspis cordyla, a limited number of workers used the truss morphometry to discriminate the stocks [8-10]. A survey of literature showed that no such work on morphometric variations using truss was carried out on C. punctatus so far, except for the work carried out by Khan et al. [11]. Therefore, the present study was carried out to find out the morphometric variations employing truss network system using modern geometric morphometric methods to segregate the phenotypic stocks of C. punctatus collected from different isolated geographical sites.

\section{Materials and Methods}

The total of 90 fish samples were collected from three different regions, that is, Gomti River at Lucknow $\left(n=30,26^{\circ} 52^{\prime}\right.$ $\left.\mathrm{N} 80^{\circ} 55^{\prime} \mathrm{E}\right)$ and ponds situated at Kolkata $\left(n=30,22^{\circ}\right.$ $\left.34^{\prime} \mathrm{N} 88^{\circ} 22^{\prime} \mathrm{E}\right)$ and Malihabad $\left(n=30,26^{\circ} 55^{\prime} \mathrm{N} 80^{\circ} 43^{\prime}\right.$ E). These regions of the country are geographically isolated 


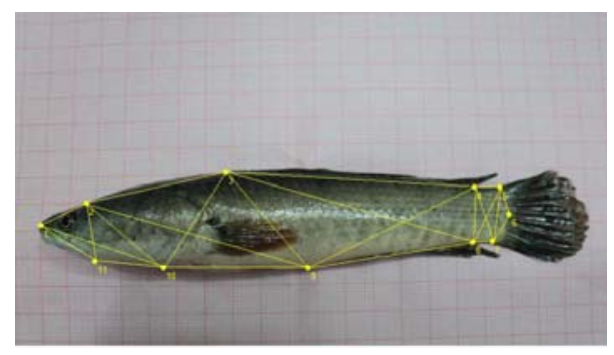

FIGURE 1: Location of 11 morphometric landmarks for constructing the truss network system on Channa punctatus.

from each other. Images of specimens of C. punctatus were taken using digital camera (Nikon 16.0 megapixels). A total of eleven morphometric landmarks (Figure 1) were digitized in software TpsDig version 1.40 [12]. For covering the entire shape of fish, two-dimensional procrustes fitting was done with software Paleontological Statistics [13] after TpsDig and 23 truss measurements were taken for morphometric study as depicted in Figure 1. Prior to data analysis, the size effect was removed from the data as the collected samples of fish were not of the same age and size. Significant correlations were observed between the size (standard length) and the morphometric truss measurements. So, $M$ transformation and then log transformation of all measurements was carried out to remove the size effect and normalization of the data, respectively. The size effect resulting was eliminated from the data using following formula [14]:

$$
M_{\mathrm{adj}}=M *\left(\frac{L_{s}}{L_{o}}\right)^{b},
$$

where $M$ is original measurement, $M_{\text {adj }}$ is size-adjusted measurement, $L_{o}$ is standard length, $L_{s}$ is the mean of standard length, and parameter $b$ was estimated for each character from observed data as the slope of regression of $\log M$ on $\log L_{o}$ using all fish in all populations. The $M$ transformed data was again checked for correlations of morphometric measurements with standard length for efficiency check of size removal. Standard length and total length were excluded from the final analysis. Both univariate and multivariate analysis of variance were carried out to test the significance of morphological variations.

After data transformation, all the truss measurements were subjected to one-way ANOVA analysis to find out the significant $(p<.05)$ morphometric truss measurements between the subpopulations of $C$. punctatus. Significant $(p<$ .05) morphometric measurements were further subjected to principal component analysis (PCA) and discriminant function analysis (DFA) to interpret the size and shape variation and for group classification, respectively. All the calculations were done with help of PAST and SPSS 12.0 software.

\section{Results and Discussion}

None of the 23 truss measurements gave significant correlation with the standard length after $M$ transformation
TABLE 1: Highly significant $(p<.001) 23$ truss measurements between the three subpopulations of $C$. punctatus in one-way ANOVA analysis.

\begin{tabular}{lcc}
\hline S. number & Morphometric measurements & $p$ value \\
\hline 1 & $1-2$ & .000 \\
2 & $1-10$ & .000 \\
3 & $1-11$ & .000 \\
4 & $2-3$ & .000 \\
5 & $2-9$ & .000 \\
6 & $2-10$ & .000 \\
7 & $2-11$ & .000 \\
8 & $3-4$ & .000 \\
9 & $3-8$ & .000 \\
10 & $3-9$ & .000 \\
11 & $3-10$ & .000 \\
12 & $4-5$ & .000 \\
13 & $4-7$ & .000 \\
14 & $4-8$ & .000 \\
15 & $4-9$ & .000 \\
16 & $5-7$ & .000 \\
17 & $5-8$ & .000 \\
18 & $5-6$ & .000 \\
19 & $7-8$ & .000 \\
20 & $6-7$ & .000 \\
21 & $8-9$ & .000 \\
22 & $9-10$ & .000 \\
23 & $10-11$ & .000 \\
\hline
\end{tabular}

indicating that allometric formula was effective in removing size effect from the data. All the 23 truss measurements were found to be highly significant $(p<.001)$ in one-way ANOVA (Table 1) and were further tested in multivariate analysis using PCA and DFA.

The principal component analysis resulted in extraction of 23 principal components. The first three components extracted accounted for a total variance of $83.25 \%, 5.33 \%$, and $3.37 \%$ by PC 1 , PC 2, and PC 3, respectively. Three separate 95\% confidence ellipses were obtained in PC 1 scatter graph on PC 2 (Figure 2). The most significant loadings on PC 1 were nearly same in magnitude and found to be positively correlated to all the measurements (Table 2). The PC 2 and PC 3 were positively and negatively correlated to all the measurements. The high components loadings of PC 2 were truss measurements $4-5,10-11,2-10,1-10$, and $1-11$, and those correlated with PC 3 were 4-5, 10-11, 9-10, 3-10, 2-10, and 1-10 (Figures 3 and 4). These measurements were mainly responsible for the variation between the three subpopulations. In discriminant function analysis (DFA), 100\% of original grouped cases were correctly classified into their respective subpopulation and two discriminant functions were formed (DF 1 and DF 2). The two functions accounted for $100 \%$ variability between the groups in which DF 1 and DF 2 explained $99.6 \%$ and $0.4 \%$ of the between-group variation for morphometric measurements. The combined group plot of DF 1 on DF 2 indicated the existence of three different 
TABLE 2: First three principal components extracted from principal component analysis.

\begin{tabular}{|c|c|c|c|c|}
\hline S. number & $\begin{array}{l}\text { Morphometric } \\
\text { measurements }\end{array}$ & PC 1 & PC 2 & PC 3 \\
\hline 1 & $1-2$ & 0.8985 & -0.1621 & 0.1589 \\
\hline 2 & $1-10$ & 0.9459 & 0.2164 & -0.1928 \\
\hline 3 & $1-11$ & 0.9282 & -0.185 & 0.01224 \\
\hline 4 & $2-3$ & 0.904 & 0.1695 & 0.009657 \\
\hline 5 & $2-9$ & 0.9589 & 0.1141 & 0.08892 \\
\hline 6 & $2-10$ & 0.9227 & 0.3027 & -0.1994 \\
\hline 7 & $2-11$ & 0.9732 & -0.07009 & 0.1261 \\
\hline 8 & $3-4$ & 0.9515 & 0.1206 & 0.1712 \\
\hline 9 & $3-8$ & 0.9661 & 0.06335 & 0.1127 \\
\hline 10 & $3-9$ & 0.9344 & 0.0342 & 0.1242 \\
\hline 11 & $3-10$ & 0.9196 & -0.09022 & 0.215 \\
\hline 12 & $4-5$ & 0.7589 & -0.5035 & -0.3887 \\
\hline 13 & $4-7$ & 0.9687 & -0.1191 & -0.09665 \\
\hline 14 & $4-8$ & 0.9677 & -0.04644 & 0.03707 \\
\hline 15 & $4-9$ & 0.954 & 0.07266 & 0.1255 \\
\hline 16 & $5-7$ & 0.9918 & 0.0384 & 0.01424 \\
\hline 17 & $5-8$ & 0.9837 & -0.02992 & 0.03465 \\
\hline 18 & $5-6$ & 0.9507 & 0.1036 & 0.02748 \\
\hline 19 & $7-8$ & 0.8632 & -0.1474 & -0.02855 \\
\hline 20 & $6-7$ & 0.8704 & 0.1604 & 0.08889 \\
\hline 21 & $8-9$ & 0.9461 & 0.01748 & 0.05125 \\
\hline 22 & $9-10$ & 0.8742 & -0.1059 & 0.3188 \\
\hline \multirow[t]{3}{*}{23} & 10-11 & 0.7943 & 0.4871 & -0.3151 \\
\hline & Total variance (\%) & 83.25 & 5.33 & 3.37 \\
\hline & $\begin{array}{l}\text { Cumulative variance } \\
(\%)\end{array}$ & 83.25 & 88.58 & 91.95 \\
\hline
\end{tabular}

phenotypic stocks of C. punctatus as three isolated group centroids were obtained in DFA (Figure 5). Examination of the pooled within-group correlations of discriminating functions and morphometric measurements revealed that measurements $5-7,3-8,5-8,2-9,4-9,4-8,8-9,3-9,3-10,1-$ 10 , and $9-10$ were mainly responsible for differences among the subpopulations (Table 3 ).

The present truss study revealed the high degree of significant morphometric heterogeneity among the subpopulations of $C$. punctatus. The univariate (one-way ANOVA) and multivariate analysis via PCA and DFA suggested three phenotypic distinct stocks of $C$. punctatus. These morphometric differences can be attributed to the fact that these three subpopulations of C. punctatus are geographically isolated from each other.

Principal component analysis laid emphasis on the effect of size on the linear dimensions of the measurements apart for explaining the shape variation in the three subpopulations. PC 1 (83.25\% variance) was positively correlated to all the morphometric traits represented by the general size but PC 2 and PC 3 explained about $5.33 \%$ and $3.37 \%$ variance, respectively, due to shape as they were strongly positively and

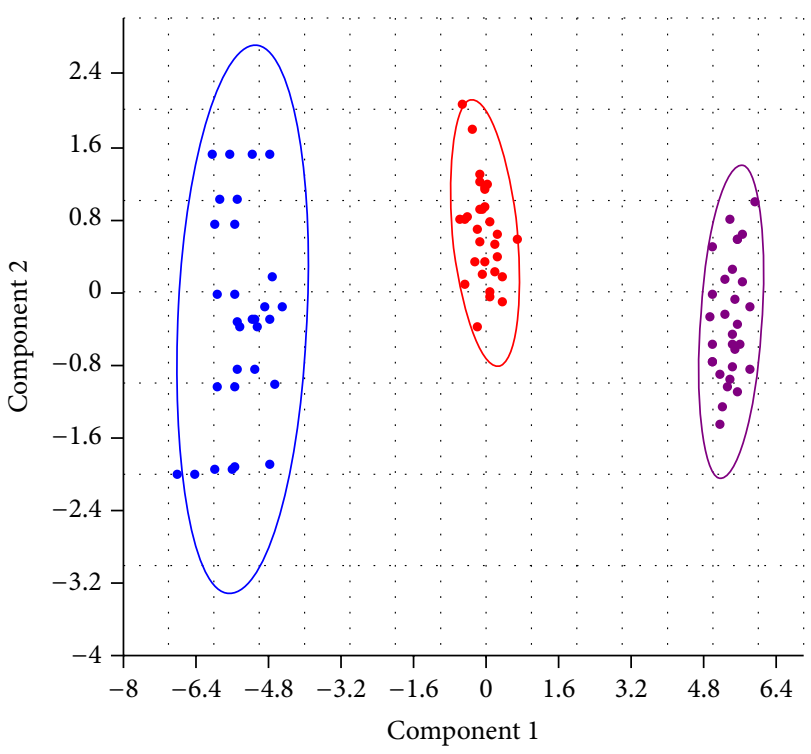

FIgURE 2: Scatter plot of PC 1 on PC 2 showing 95\% confidence ellipses of three subpopulations of C. punctatus. Red, violet, and blue colours indicate Gomti River, pond of Malihabad, and pond of Kolkata subpopulation, respectively.

TABLE 3: Pooled within-groups correlations between discriminating morphometric measurements and standardized canonical discriminant functions. Variables ordered by absolute size of correlation within function.

\begin{tabular}{lccc}
\hline S. number Morphometric measurements & Function 1 & Function 2 \\
\hline 1 & $5-7$ & $.173^{*}$ & .022 \\
2 & $3-8$ & $.152^{*}$ & -.085 \\
3 & $5-8$ & $.136^{*}$ & .061 \\
4 & $2-9$ & $.117^{*}$ & -.094 \\
5 & $4-9$ & $.114^{*}$ & -.098 \\
6 & $4-8$ & $.094^{*}$ & -.013 \\
7 & $8-9$ & $.092^{*}$ & -.022 \\
8 & $3-9$ & $.083^{*}$ & .007 \\
9 & $3-10$ & $.072^{*}$ & .061 \\
10 & $1-10$ & $.071^{*}$ & .021 \\
11 & $9-10$ & $.058^{*}$ & .052 \\
12 & $1-2$ & .072 & $.362^{*}$ \\
13 & $6-7$ & .064 & $-.301^{*}$ \\
14 & $2-11$ & .135 & $.277^{*}$ \\
15 & $4-5$ & .033 & $.235^{*}$ \\
16 & $3-4$ & .134 & $-.160^{*}$ \\
17 & $1-11$ & .067 & $.159^{*}$ \\
18 & $2-3$ & .065 & $-.148^{*}$ \\
19 & $5-6$ & .093 & $-.144^{*}$ \\
20 & $4-7$ & .086 & $.113^{*}$ \\
21 & $7-8$ & .047 & $.113^{*}$ \\
22 & $2-10$ & .064 & $-.087^{*}$ \\
23 & $10-11$ & .036 & $-.066^{*}$ \\
\hline
\end{tabular}

${ }^{*}$ Largest absolute correlation between each variable and any discriminant function. 


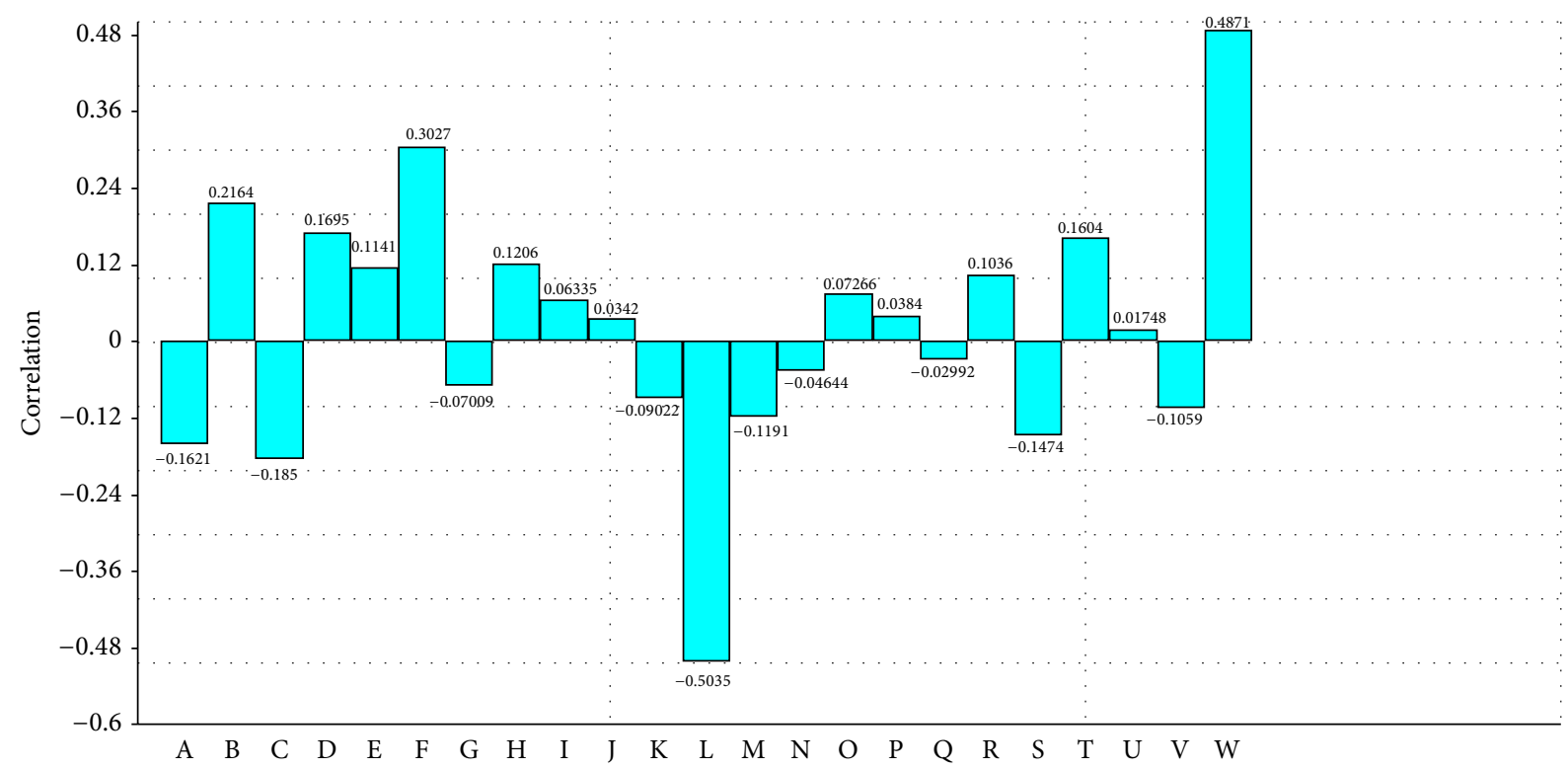

FIGURE 3: PCA loadings of PC 2 and its correlation with various morphometric parameters.

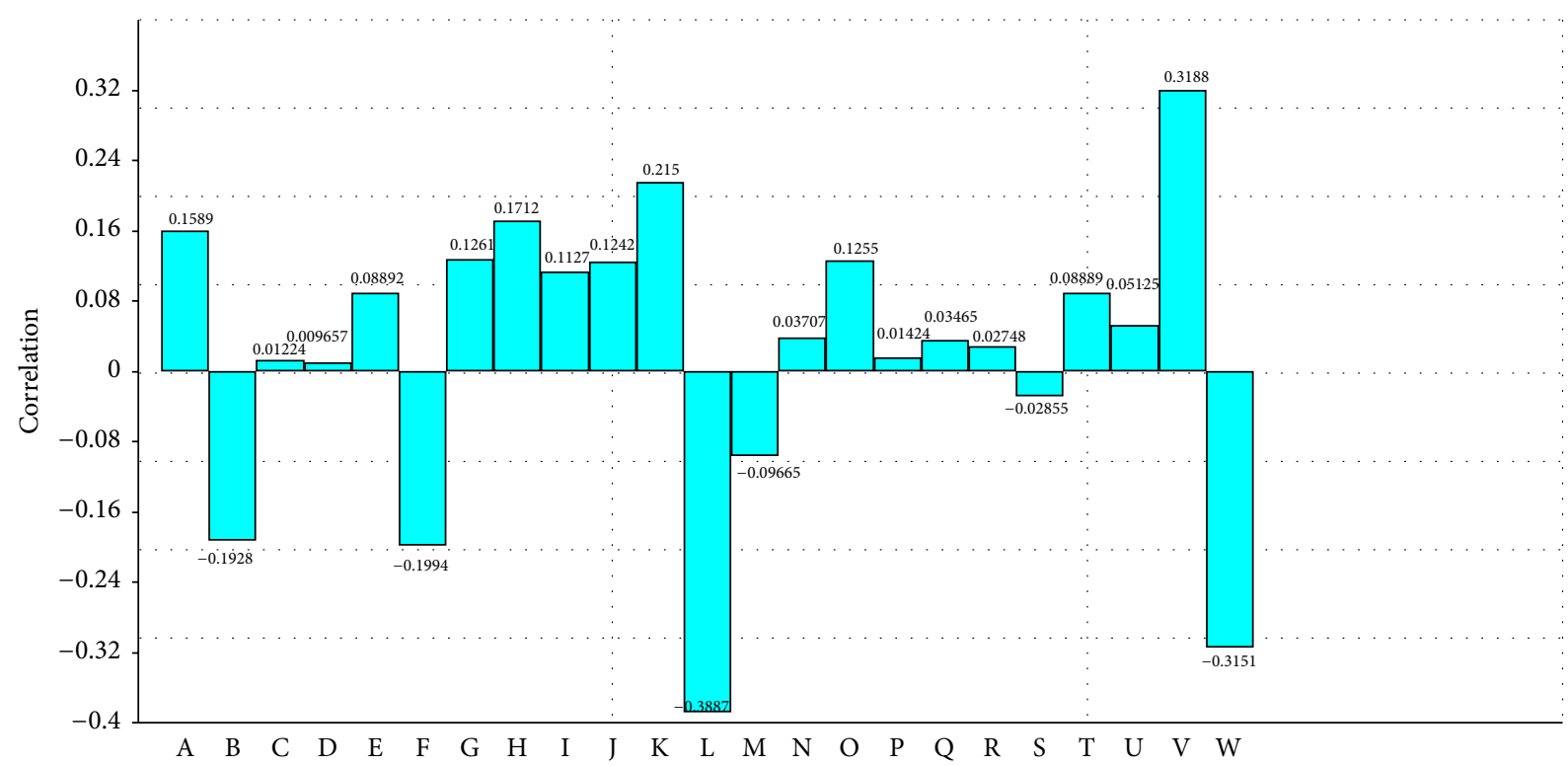

FIGURE 4: PCA loadings of PC 3 and its correlation with various morphometric parameters.

negatively correlated to morphometric traits. The coefficients of same sign in PCs and coefficients with negative and positive signs of any section of PCs are indicative of "size variation" and "shape variation," respectively [15-18].

The consistent differences in the morphometric measurements between the three subpopulations of C. punctatus suggested the restricted intermingling among the subpopulations of Lucknow, Malihabad, and Kolkata which was also supported by the nonoverlapping and isolated group centroids in DFA. Saila and Flowers [19] used DFA to study the geographic variation by analyzing the morphometrics of American lobster. The existence of different strains of Indian major carp Catla catla was reported by NBFGR [20] and emphasized that it was due to complete geographical isolation without any intermixing. The morphometric variations in the different subpopulations of $C$. punctatus in the present study may be due to geographical isolation and different environmental conditions. However, it is generally assumed that these differences may be genetically related or might be associated with phenotypic plasticity in response to different environmental factors of various habitats [21]. Moreover, the variations recorded among three subpopulations of $C$. punctatus could be a result of phenotypic plasticity expressed in response to the environmental conditions. The present 


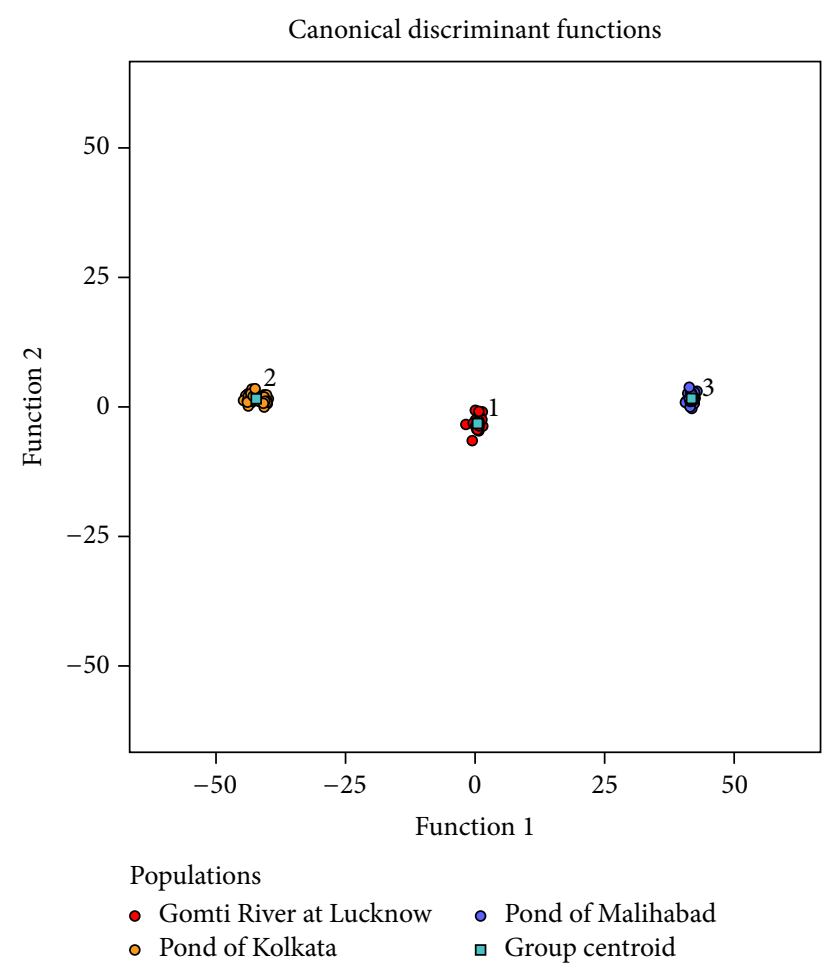

FIGURE 5: Group centroids of the three subpopulations of $C$. punctatus in DFA combined groups plot.

results are similar to those of Pathak et al. [22] who reported morphometric variation in Macrognathus pancalus from two different river basins of India. Khan et al. [11] also discriminated the subpopulations of $C$. punctatus collected from three different rivers (Ganga, Yamuna, and Gomti) of India where the differences were in the head, abdomen, and caudal peduncle regions. The major contributions to DFA and PCA were the measurements belonging to these regions including the high allometric shape contributions from diagonal body measurements.

\section{Conclusion}

These current findings in the truss analysis indicated significant morphometric variations and thus the presence of three different phenotypic stocks of C. punctatus.

\section{Conflict of Interests}

The authors declare that there is no conflict of interests regarding the publication of this paper.

\section{Acknowledgments}

The authors thank the Head of the Department of Zoology, University of Lucknow, for providing facility and one of the authors is thankful to the Department of Science and Technology (DST-PURSE) for providing him fellowship.

\section{References}

[1] S. X. Cadrin, "Advances in morphometric identification of fishery stocks," Reviews in Fish Biology and Fisheries, vol. 10, no. 1, pp. 91-112, 2000.

[2] A. Kashyap, M. Awasthi, and M. Serajuddin, "Intraspecific diversity of freshwater murrel, Channa punctatus," International Journal of Fisheries and Aquatic Studies, vol. 3, no. 2, pp. 166-173, 2015.

[3] J. Verma, A. Kashyap, and M. Serajuddin, "Phylogeny based on truss analysis in five populations of freshwater catfish: Clupisoma garua," International Journal of Science and Research, vol. 3, no. 8, pp. 1414-1418, 2014.

[4] A. Kashyap, M. Awasthi, and M. Serajuddin, "Geographic morphometric variations of freshwater murrel, Channa punctatus from northern and eastern parts of India," Proceedings of the National Academy of Sciences, India Section B: Biological Sciences, pp. 1-7, 2014.

[5] L. Hauser, G. R. Carvalho, and T. J. Pitcher, "Morphological and genetic differentiation of the African clupeid Limnothrissa miodon 34 years after its introduction to Lake Kivu," Journal of Fish Biology, vol. 47, pp. 127-144, 1995.

[6] D. G. Bembo, G. R. Carvalho, N. Cingolani, E. Arneri, G. Giannetti, and T. J. Pitcher, "Allozymic and morphometric evidence for two stocks of the European anchovy Engraulis encrasicolus in Adriatic waters," Marine Biology, vol. 126, no. 3, pp. 529-538, 1996.

[7] C. Turan, "A note on the examination of morphometric differentiation among fish populations: the truss system," Turkish Journal of Zoology, vol. 23, pp. 259-264, 1999.

[8] N. C. Ujjainia and M. P. S. Kohli, "Landmark-based morphometric analysis for selected species of Indian major carp (Catla catla, Ham. 1822)," International Journal of Food, Agriculture and Veterinary Science, vol. 1, pp. 64-74, 2011.

[9] P. Jayasankar, P. C. Thomas, M. P. Paulton, and J. Mathew, "Morphometric and genetic analyzes of Indian mackerel (Rastrelliger kanagurta) from peninsular India," Asian Fisheries Science, vol. 17, pp. 201-215, 2004.

[10] A. M. Sajina, S. K. Chakraborty, A. K. Jaiswar, D. G. Pazhayamadam, and D. Sudheesan, "Stock structure analysis of Megalaspis cordyla (Linnaeus, 1758) along the Indian coast based on truss network analysis," Fisheries Research, vol. 108, no. 1, pp. 100-105, 2011.

[11] M. A. Khan, K. Miyan, and S. Khan, "Morphometric variation of snakehead fish, Channa punctatus, populations from three Indian rivers," Journal of Applied Ichthyology, vol. 29, no. 3, pp. 637-642, 2013.

[12] F. J. Rholf, TpsDig, Version 1.40, Department of Ecology and Evolution, State University of New York, New York, NY, USA, 2004.

[13] O. Hammer, D. A. T. Harper, and P. D. Ryan, "PAST: paleontological statistics software package for education and data analysis," Palaeontologia Electronica, vol. 4, article 9, 2001.

[14] N. G. Elliott, K. Haskard, and J. A. Koslow, "Morphometric analysis of orange roughy (Hoplostethus atlanticus) off the continental slope of southern Australia," Journal of Fish Biology, vol. 46, no. 2, pp. 202-220, 1995.

[15] P. Jolicoeur and J. E. Mosimann, "Size and shape variation in the painted turtle. A principal component analysis," Growth, vol. 24, pp. 339-354, 1960

[16] J. M. Humphries, F. L. Bookstein, B. Chernoff, G. R. Smith, R. L. Elder, and S. G. Poss, "Multivariate discrimination by shape in 
relation to size," Systematic Biology, vol. 30, no. 3, pp. 291-308, 1981.

[17] F. L. Bookstein, "'Size and Shape': a comment on semantics," Systematic Biology, vol. 38, no. 2, pp. 173-180, 1989.

[18] P. Sundberg, "Shape and size-constrained principal components analysis," Systematic Zoology, vol. 38, no. 2, pp. 166-168, 1989.

[19] S. B. Saila and J. M. Flowers, "Geographic morphometric variation in the American lobster," Systematic Zoology, vol. 18, no. 3, pp. 330-338, 1969.

[20] National Bureau of Fish Genetic Resources, Annual Report of National Bureau of Fish Genetic Research, National Bureau of Fish Genetic Resources, Lucknow, India, 2001.

[21] A. G. Murta, "Morphological variation of horse mackerel (Trachurus trachurus) in the Iberian and North African Atlantic: implications for stock identification," ICES Journal of Marine Science, vol. 57, no. 4, pp. 1240-1248, 2000.

[22] B. C. Pathak, J. I. Mir, and M. Serajuddin, "Morphometric variation among barred spiny eel, Macrognathus pancalus (Hamilton 1822), populations from the Ganges and Brahmaputra river basin, India by using geomorphometrics," Journal of Biology, vol. 3, no. 1, pp. 15-20, 2013. 

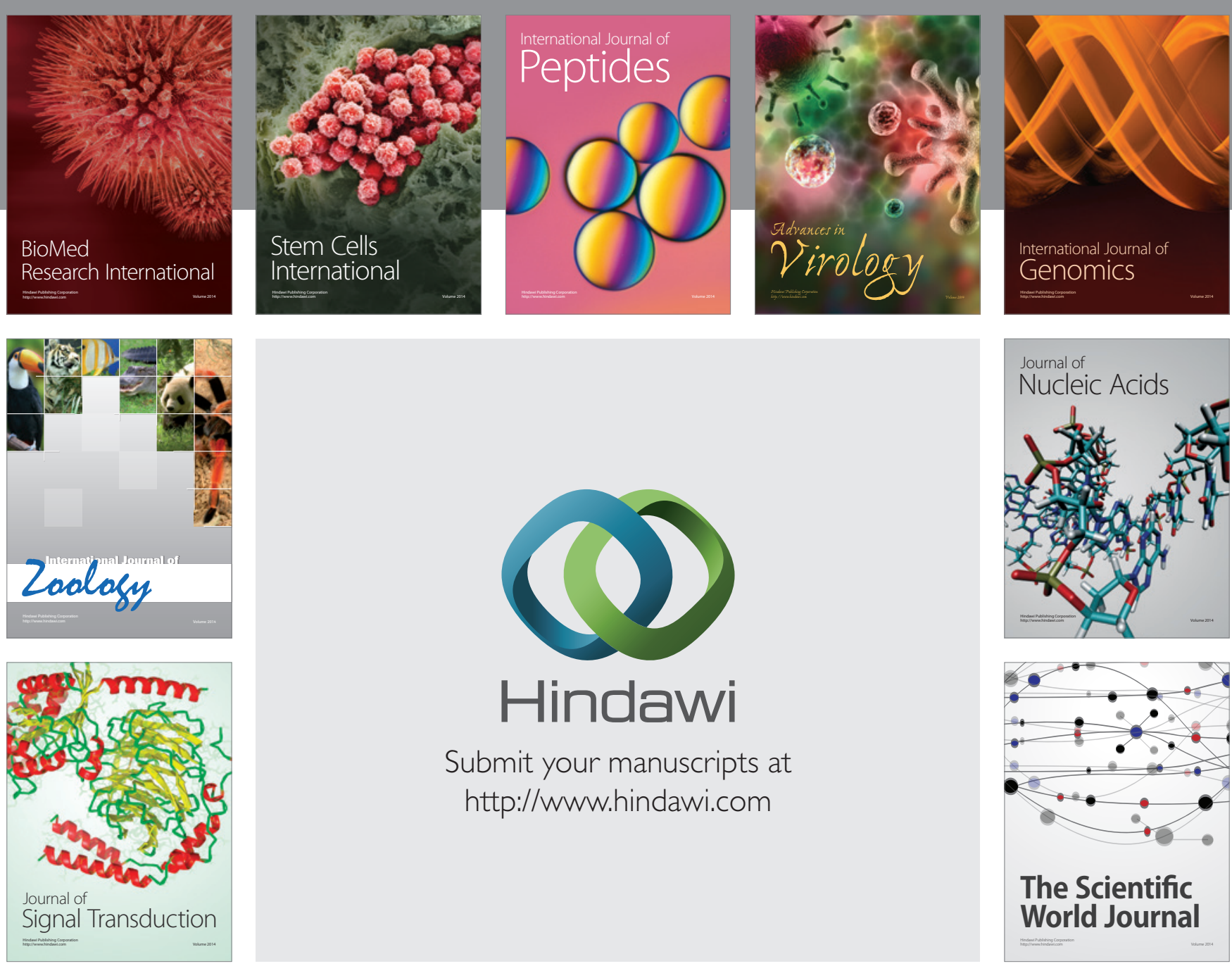

Submit your manuscripts at

http://www.hindawi.com
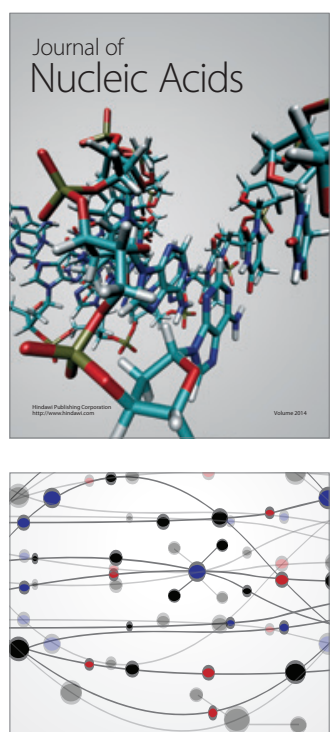

The Scientific World Journal
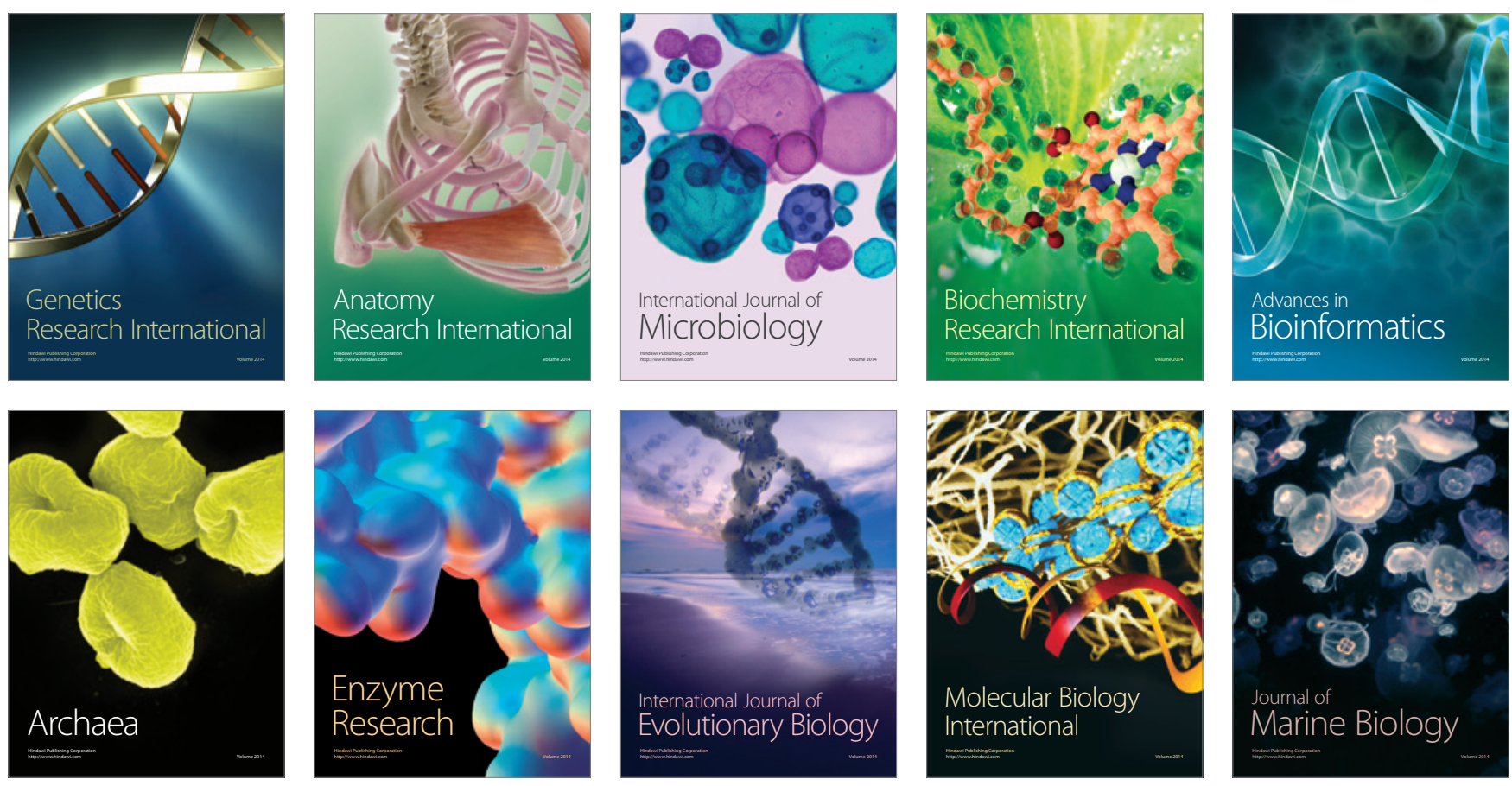